\title{
The effects of oral arginine on its metabolic pathways in Sprague-Dawley rats
}

\author{
Sarah Martin and Kaushik Desai* \\ Department of Anatomy, Physiology E Pharmacology, University of Saskatchewan, Saskatoon, SK S7N 5E5, Canada
}

(Submitted 26 April 2019 - Final revision received 30 September 2019 - Accepted 16 October 2019 - First published online 18 December 2019)

\section{Abstract}

Oral arginine supplements are popular mainly for their presumed vasodilatory benefit. Arginine is a substrate for at least four enzymes including nitric oxide synthase (NOS) and arginase, but the impact of oral supplements on its different metabolic pathways is not clear. Deficiencies of arginine-metabolising enzymes are associated with conditions such as hyperammonaemia, endothelial dysfunction, central nervous system and muscle dysfunction, which complicate the use of oral arginine supplements. We examined the effect of L-arginine (L-Arg) and D-arginine (D-Arg), each at $500 \mathrm{mg} / \mathrm{kg}$ per d in drinking water administered for 4 weeks to separate groups of 9-week-old male SpragueDawley rats. We quantified the expression of enzymes and plasma, urine and organ levels of various metabolites of arginine. L-Arg significantly decreased cationic transporter-1 expression in the liver and the ileum and increased endothelial NOS expression in the aorta and the kidney and plasma nitrite levels, but did not affect the mean arterial pressure. L-Arg also decreased the expression of arginase II in the ileum, arginine:glycine amidinotransferase in the liver and the kidney and glyoxalase I in the liver, ileum and brain, but increased the expression of arginine decarboxylase and polyamines levels in the liver. D-Arg, the supposedly inert isomer, also unexpectedly affected the expression of some enzymes and metabolites. In conclusion, both L- and D-Arg significantly affected enzymes and metabolites in several pathways that use arginine as a substrate and further studies with different doses and treatment durations are planned to establish their safety or adverse effects to guide their use as oral supplements.

\section{Key words: Arginine supplements: Nitric oxide: Arginase: D-Arginine: Creatine}

Many amino acids including arginine are commonly used as oral supplements for various reasons, including as a nutrient. L-Arginine (L-Arg) is a semi-essential amino acid which serves as a substrate for a variety of enzymes ${ }^{(1)}$. The more well-known nitric oxide synthases (NOS) use L-Arg, but not D-arginine (D-Arg), to produce nitric oxide (NO), a vasodilator and L-citrulline ${ }^{(2)}$. The endothelial isoform of NOS (eNOS) is an important regulator of vascular tone and blood flow and a major reason for the popularity of arginine supplements ${ }^{(3-5)}$. Arginase is a major enzyme that uses L-Arg produced in the urea cycle to produce ornithine and urea and thus plays an important role in ammonia detoxification ${ }^{(1)}$. While arginase 1 is mainly present in the liver, arginase 2 in the kidney and the intestines is believed to regulate polyamine, proline and NO synthesis $^{(1)}$. Arginase has been shown to compete with eNOS for L-Arg as a substrate, resulting in endothelial dysfunction in some situations ${ }^{(6)}$. Arginine:glycine amidinotransferase (GATM) converts arginine into creatine via guanidinoacetate $\mathrm{N}$-methyltransferase ${ }^{(7)}$. Arginine is also a substrate for arginine decarboxylase (ADC) which produces agmatine, a putative neurotransmitter ${ }^{(8,9)}$.
Oral supplements have become more popular after the discovery of L-Arg as a precursor for the vasodilatory NO. Thus, it is used by healthy people and athletes to increase exercise capacity ${ }^{(5,10)}$. Hoping to improve vasodilation, arginine supplements have been used in patients with mitochondrial myopathy, encephalopathy, lactic acidosis and stroke (MELAS $^{(11)}$, hypercholesterolaemia ${ }^{(4)}$, diabetic patients ${ }^{(12)}$ and hypertension ${ }^{(13)}$. Interestingly, arginine supplements did not affect blood pressure in healthy humans ${ }^{(14)}$. Other conditions for which it has been shown to be beneficial include obesity $^{(15)}$ and reduction of plasma lipids and glucose in humans ${ }^{(15-17)}$. Arginine supplements have also been reported to be unsuccessful in affecting eNOS activity and improving vasodilation in several conditions ${ }^{(18-21)}$.

Despite the increasing popularity of oral arginine supplements, there is a lack of knowledge about an optimum dose or effects of oral arginine on its multiple enzymes and metabolites. Studies and information about the impact of oral arginine supplements on its metabolic pathways are available only in bits and pieces, and there are very few studies which have mainly reported effects on a single metabolic pathway ${ }^{(22,23)}$.

Abbreviations: ADC, arginine decarboxylase; ADMA, asymmetric dimethyl arginine; CAT-1, cationic transporter-1; D-Arg, D-arginine; eNOS, endothelial nitric oxide synthase; GATM, glycine amidinotransferase; L-Arg, L-arginine; MG, methylglyoxal; NOS, nitric oxide synthase; ZDF, Zucker diabetic fatty. 
Moreover, many studies do not include D-Arg, the supposedly inert isomer. This was our rationale to undertake a comprehensive study to determine the effect of oral L-Arg and D-Arg on its multiple metabolic pathways in normal Sprague-Dawley rats. Since our study involved examining several organ and plasma samples, human studies were not feasible. The rat was chosen as a model because abundant data on its physiology are available and it closely resembles human physiology ${ }^{(24)}$. Our objectives were to examine the impact of oral arginine supplements on its metabolic enzymes and their metabolites in all metabolic pathways that utilise L-Arg as a substrate. Since arginine is a scavenger of methylglyoxal $(\mathrm{MG})^{(23)}$, a reactive metabolite of glucose and fructose, we also examined the impact on the glyoxalase enzymes, which degrade MG into D-lactate.

\section{Materials and methods}

\section{Animals}

A total of twenty-seven male, 9-week-old, Sprague-Dawley rats were purchased from Charles River Canada for use according to a protocol (no. 20160059) approved by the Animal Care Committee at the University of Saskatchewan, following guidelines of the Canadian Council on Animal Care and the ARRIVE guidelines ${ }^{(25)}$. The rats were housed in the state-ofthe-art vivarium facilities of the Health Sciences building. They were fed a standard laboratory rat diet (Prolab ${ }^{\circledR} \mathrm{RMH}$ 3000 , LabDiet) containing arginine at $1.37 \%$ in a protein content of $22.5 \%$. After 1 week of acclimatisation, the rats were randomly assigned to one of the three treatment groups with nine rats per group: (1) control: plain drinking water, (2) L-Arg: $500 \mathrm{mg} / \mathrm{kg}$ per d via drinking water and (3) D-Arg: $500 \mathrm{mg} / \mathrm{kg}$ per d via drinking water. The treatment was administered for 4 weeks. The dose of $500 \mathrm{mg} / \mathrm{kg}$ per $\mathrm{d}$ was selected from the dose range used in rats ${ }^{(26-28)}$ and humans ${ }^{(14,29)}$. The group size was chosen based on data from previous projects and protocols to ensure robust statistical data. During this time, rats were individually housed to allow for individual daily water intake to be recorded. The body weight was recorded every other day. The daily water intake and body weight were used to calculate the dose of arginine for each rat, which was adjusted every other day in the drinking water. Arginine free base (L-Arg, catalogue no. W381918, Sigma-Aldrich Canada Ltd; D-Arg, catalogue no. GM7267, Glentham Life Sciences) was dissolved in the drinking water, and the highly alkaline $\mathrm{pH}$ was adjusted to 7.4 with hydrochloric acid.

After 4 weeks of treatment, a terminal experiment was performed during daytime in the Health Sciences vivarium facilities as follows. The rat was placed in a metabolic cage overnight for $16 \mathrm{~h}$ prior to the experiment, and urine was collected. The rats were anaesthetised using isoflurane (Forane, $2-4 \%$ in $\mathrm{O}_{2}$ ), to minimise depression of cardiorespiratory systems, and the right carotid artery and left jugular vein were cannulated to record the mean arterial pressure and collect blood samples, respectively. The mean arterial pressure was recorded for 20 min using the Powerlab (AD Instruments Inc.) and Chart software. Following blood pressure recording, the heart was cut open to cause exsanguination and various organs/tissues were collected and frozen in liquid $\mathrm{N}_{2}$ and stored at $-80^{\circ} \mathrm{C}$.

\section{Arginine, lysine and citrulline assays}

Arginine levels were measured using a rat arginine elisa kit (MyBiosource Inc.; catalogue no. MBS751058), which employs a double antibody sandwich technique. The plate is coated with a specific anti-arginine monoclonal antibody. Lysine levels were measured using a fluorometric lysine assay kit (Biovision Inc.; catalogue no. K2005-100). The assay is based on selective enzymatic metabolism of lysine to yield a final fluorogenic probe. Citrulline levels were measured using a colourimetric assay kit (Abcam; catalogue no. ab242292).

\section{Western blotting}

Western blotting was performed as described previously ${ }^{(23)}$ on tissue lysates. The protein concentration of the supernatant was determined using the DC Protein assay (Bio-Rad Laboratories). The protein loading concentration for each antibody was determined by trying concentrations ranging from 30 to $75 \mu \mathrm{g}$ and selecting a concentration which gave a clean signal that was within the liner range of the imaging software. The protein samples from different organs/tissues were separated (50-75 $\mu \mathrm{g}$ of protein per well) on a 4-20\% SDS-polyacrylamide gel (Bio-Rad Laboratories) via electrophoresis and wetelectrotransferred onto a 0.45 polyvinylidene difluoride membrane (GE Healthcare Life Sciences) and blocked using non-fat milk or $5 \%$ bovine serum albumin (Sigma Canada) in Tris-buffered saline-Tween buffer for $1 \mathrm{~h}$ at room temperature for arginase I/II and eNOS, respectively. Blots were then incubated at $4{ }^{\circ} \mathrm{C}$ overnight using appropriate primary antibodies: SLC7A1 (cationic transporter-1 (CAT-1), 1:1000, Antibodies-Online Inc.); eNOS (1:1000, BD Transduction Laboratories); arginase I and arginase II (1:1000); ADC (1:500 to 1:1000, Abcam Inc.), agmatinase (1:1000, Abcam Inc.), GATM (1:250, Abcam Inc.), glyoxalase (1:200, Abcam Inc.) and $\beta$-actin (1:8000, Abcam Inc.). This was followed by an $1 \mathrm{~h}$ incubation at room temperature with horseradish peroxidase-conjugated secondary antibody (Bio-Rad Laboratories). Following a thorough washing with Tris-buffered salineTween, the immunoreactive proteins were detected using Clarity Western Enhanced Chemiluminescence Blotting Substrates (Bio-Rad Laboratories). Finally, the images were analysed via densitometry using the GeneTools software (Syngene). If the separation of the bands for the target protein and $\beta$-actin was more, dual staining was performed on the same gel. If the bands for the target protein and $\beta$-actin were too close, staining was performed on two separate gels loaded with equal amounts of proteins, mounted in the same cassette and run at the same time. We tried stripping the membrane of the target protein and then staining for $\beta$-actin, but the results were not satisfactory. Precision Plus Dual Colour Protein standards (Bio-Rad Laboratories Ltd) were always loaded in the first lane to ensure that the detected bands were at the expected molecular weight. 


\section{Nitric oxide synthase activity assay}

NOS activity was determined using a NOS activity assay kit (Biovision Inc.). Like the nitrite/nitrate assay, this kit uses the Griess reaction to convert NO produced by NOS enzymes into a coloured product for which absorbance can be read at $540 \mathrm{~nm}$. In brief, cold NOS assay buffer was added to tissue samples and homogenised on ice. A sample $(30 \mu \mathrm{l})$ was added to the wells of a ninety-six-well plate followed by $40 \mu \mathrm{l}$ of reaction mix. After $1 \mathrm{~h}$ incubation at $37^{\circ} \mathrm{C}$, an additional $95 \mu \mathrm{l}$ of NOS assay buffer was added along with $5 \mu \mathrm{l}$ of enhancer. After $10 \mathrm{~min}$ incubation at room temperature, $50 \mu \mathrm{l}$ of each of Griess Reagents 1 and 2 was added. Following 10 min incubation at room temperature, the absorbance was read at $540 \mathrm{~nm}$.

\section{Nitrite/nitrate assay}

Levels of nitrite and nitrate, as indicators of NO production, were measured using a colourimetric assay kit based on the Griess reaction (Cayman Chemicals) ${ }^{(23)}$. The assay kit first converts nitrate to nitrite via nitrate reductase, and the Griess reagent converts nitrite to a deep purple azo compound. The optical density was measured at $540 \mathrm{~nm}$ on a UV spectrophotometer (Multiskan Ascent, ThermoFisher).

\section{Arginase activity assay}

Arginase activity was measured using an arginase activity assay kit (Sigma-Aldrich) ${ }^{(23)}$. Arginase converts arginine to ornithine and urea. In brief, plasma samples were filtered to deplete urea from the sample. Tissue homogenates did not require further preparation. Samples were then loaded into a 96-well plate along with $10 \mu \mathrm{l}$ of substrate buffer. The plate was allowed to incubate for $2 \mathrm{~h}$ at $37^{\circ} \mathrm{C}$ after which $200 \mu \mathrm{l}$ of urea reagent was added to stop the reaction. Optical density was then measured at $430 \mathrm{~nm}$.

\section{Urea assay}

Urea is a product of arginine breakdown by arginase. Urea levels were determined in plasma, urine and various organs using a urea assay kit (Abcam Inc.). In short, $25 \mu$ of sample and $25 \mu \mathrm{l}$ of urea assay buffer were added to each well followed by $50 \mu \mathrm{l}$ of reaction mix. Following a $60 \mathrm{~min}$ incubation at $37^{\circ} \mathrm{C}$, optical density was measured at $570 \mathrm{~nm}$.

\section{Arginine decarboxylase assay}

Arginine decarboxylase levels were quantified in the plasma, ileum and kidney using an ELISA bioassay kit (catalogue no. abx251853, Abbexa Ltd, Cambridge Science Park) as per the manufacturer's instructions. This kit is based on sandwich enzyme-linked immunosorbent assay with an absorbance read at $450 \mathrm{~nm}$.

\section{Total polyamines assay}

Total polyamine (putrescine, spermidine, and spermine) levels were measured using a total polyamine fluorometric assay kit (catalogue no. K475-100, BioVision Inc.) according to the manufacturer's instructions. The enzyme mix generates hydrogen peroxide which is detected with a fluorometric probe at excitation/emission wavelengths of 535/587 nm.

\section{Creatinine assay}

Creatinine levels in the organs and plasma were measured using a Sigma-Aldrich colourimetric creatinine assay kit (Sigma-Aldrich; MAK080). This assay kit determines creatinine concentration by a coupled enzyme reaction, which then results in a colourimetric (spectrophotometry at optical density $=570 \mathrm{~nm}$ ) product, proportional to the creatinine present.

\section{Glyoxalase activity}

The activity of glyoxalase-I, the rate-limiting enzyme that converts MG to S-lactoylglutathione, was measured by means of an activity assay kit (Sigma-Aldrich). The absorbance of the coloured product was read at $240 \mathrm{~nm}$ using a UV spectrophotometer.

\section{Methylglyoxal HPLC}

MG was measured by a specific and sensitive HPLC method as described earlier ${ }^{(23)}$. MG was derivatised with $o$-phenylenediamine to form the quinoxaline product, 2-methylquinoxaline, which is very specific for MG. The 2-methylquinoxaline and the internal standard 5-methylquinoxaline were quantified on a Hitachi D-7000 HPLC system (Hitachi, Ltd) via a Symmetry C18 column (3.9 $\mathrm{mm} \times 150 \mathrm{~mm}$ and $4 \mu \mathrm{m}$ particle diameter; Waters Corp.).

\section{D-Lactate assay}

D-Lactate was measured using a D-lactate colorimetric assay kit from Sigma-Aldrich (catalogue no. MAK058-1KT). The absorbance of the fluorescent product, D-lactate hydrogenase, was measured at $450 \mathrm{~nm}$ using a spectrophotometric multi-well plate reader.

\section{Statistical analysis}

The results were analysed using Graphpad PRISM software version 6 and one-way ANOVA with a post hoc test of multiple comparisons. A $P$ value of $<0.05$ was taken as significant, and the results are expressed as mean values with their standard errors. Eight rats were included in each treatment group to obtain valid statistical data and account for unexpected mortality during 4 weeks of treatment. The sample size was chosen based on previous experimental protocols using high carbohydrate diet treatments. We have done a power analysis using G*Power (version 3.1.9.4). For our results from at least four different parameters measured (significant and NS) and with a $P=0.05$ and a power of 0.80 we got actual power values above 0.95 and a total sample size ranging from six to fifteen, which justifies our total sample size of $25(8+9+8)$.

\section{Results}

Oral arginine did not affect the age-related gain in body weight

The body weights, expressed as mean values with their standard errors in $\mathrm{g}$, at the start of treatment (10 weeks) and completion of 
Table 1. Effect of oral arginine on arginine levels, nitric oxide synthase (NOS) activity and nitrate + nitrite levelsł (Mean values with their standard errors; $n$ values)

\begin{tabular}{|c|c|c|c|c|c|c|c|c|c|}
\hline & \multicolumn{3}{|c|}{ Control } & \multicolumn{3}{|c|}{ L-Arginine } & \multicolumn{3}{|c|}{ D-Arginine } \\
\hline & Mean & SEM & $n$ & Mean & SEM & $n$ & Mean & SEM & $n$ \\
\hline \multicolumn{10}{|l|}{ Arginine } \\
\hline Plasma $(\mu \mathrm{m})$ & 141 & 13 & 4 & 127 & 5 & 5 & 123 & 6 & 5 \\
\hline Liver (ng/mg protein) & 5.7 & 0.4 & 6 & $7 \cdot 2$ & 0.9 & 6 & $6 \cdot 3$ & 0.7 & 6 \\
\hline Ileum ( $\mathrm{ng} / \mathrm{mg}$ protein) & 43.9 & 2.5 & 6 & $47 \cdot 0$ & 4.4 & 7 & 47.6 & $5 \cdot 3$ & 7 \\
\hline Kidney (ng/mg protein) & $7 \cdot 9$ & $1 \cdot 7$ & 5 & 8.0 & $2 \cdot 2$ & 5 & 6.5 & 0.4 & 5 \\
\hline Brain (ng/mg protein) & $62 \cdot 0$ & 6.5 & 6 & $66 \cdot 2$ & 4.8 & 6 & $66 \cdot 7$ & 5.9 & 6 \\
\hline \multicolumn{10}{|l|}{ NOS activity } \\
\hline Aorta $(\mathrm{pmol} / \mathrm{min}$ per $\mu \mathrm{g}$ protein) & 0.09 & 0.01 & 6 & 0.14 & 0.02 & 9 & 0.11 & 0.01 & 8 \\
\hline Liver (pmol/min per $\mu$ g protein) & 0.36 & 0.04 & 6 & 0.36 & 0.03 & 6 & 0.34 & 0.05 & 6 \\
\hline Ileum (pmol/min per $\mu \mathrm{g}$ protein) & 0.14 & 0.02 & 4 & 0.14 & 0.03 & 5 & 0.14 & 0.02 & 6 \\
\hline Kidney (pmol/min per $\mu$ g protein) & $0 \cdot 18$ & 0.01 & 6 & 0.19 & 0.01 & 6 & 0.17 & 0.01 & 6 \\
\hline Brain (pmol/min per $\mu \mathrm{g}$ protein) & 0.23 & 0.04 & 6 & 0.17 & 0.01 & 6 & $0 \cdot 20$ & 0.03 & 6 \\
\hline Heart (pmol/min per $\mu \mathrm{g}$ protein) & 0.05 & 0.01 & 6 & 0.04 & 0.002 & 6 & 0.05 & 0.001 & 6 \\
\hline Lungs (pmol/min per $\mu \mathrm{g}$ protein) & 0.06 & 0.001 & 7 & 0.06 & 0.003 & 7 & $0.07^{*} \dagger$ & 0.005 & 7 \\
\hline Skeletal muscle (pmol/min per $\mu \mathrm{g}$ protein) & 0.04 & 0.01 & 8 & 0.03 & 0.002 & 9 & 0.03 & 0.004 & 8 \\
\hline \multicolumn{10}{|l|}{ Nitrate + nitrite $(\mu \mathrm{mol} / \mathrm{mg}$ protein $)$} \\
\hline Aorta ( $\mu \mathrm{mol} / \mathrm{mg}$ protein) & $2 \cdot 4$ & 0.5 & 6 & 2.9 & 0.7 & 7 & 1.7 & 0.2 & 8 \\
\hline Liver ( $\mu \mathrm{mol} / \mathrm{mg}$ protein) & 0.5 & 0.1 & 7 & 0.6 & 0.1 & 9 & 0.9 & 0.1 & 8 \\
\hline Ileum ( $\mu \mathrm{mol} / \mathrm{mg}$ protein) & 1.0 & 0.1 & 7 & 1.2 & 0.1 & 8 & 0.9 & 0.1 & 8 \\
\hline Kidney ( $\mu \mathrm{mol} / \mathrm{mg}$ protein) & $1 \cdot 1$ & 0.2 & 8 & $1 \cdot 2$ & 0.1 & 9 & 1.5 & 0.4 & 6 \\
\hline Brain ( $\mu \mathrm{mol} / \mathrm{mg}$ protein) & 0.9 & 0.1 & 8 & $1 \cdot 0$ & 0.2 & 9 & $1 \cdot 1$ & 0.1 & 8 \\
\hline Lungs ( $\mu \mathrm{mol} / \mathrm{mg}$ protein) & 0.6 & 0.1 & 8 & 0.5 & 0.1 & 9 & 0.3 & 0.1 & 8 \\
\hline Skeletal muscle ( $\mu \mathrm{mol} / \mathrm{mg}$ protein) & 0.9 & 0.2 & 7 & 0.8 & 0.1 & 9 & 0.8 & 0.2 & 8 \\
\hline
\end{tabular}

${ }^{*} P<0.05$ v. respective control group.

$\dagger P<0.05 \mathrm{v}$. respective L-arginine group.

$\ddagger$ Male Sprague-Dawley rats ( 10 weeks old) were treated with L-arginine or D-arginine in drinking water ( $500 \mathrm{mg} / \mathrm{kg}$ per d) for 4 weeks. Assay kits were used to measure arginine levels, NOS activity and nitrate + nitrite levels.

4 weeks of treatment (14 weeks), respectively, were as follows: control: 325 (SEM 8) g and 531 (SEM 11) g ( $n$ 8); L-Arg-treated group: 321 (SEM 9) g and 543 (SEM 11$) \mathrm{g}(n$ 9); D-Arg-treated group: 367 (SEM 4) g and 554 (SEM 9) $\mathrm{g}(n$ 8).

\section{Oral L-arginine, but not D-arginine, significantly resulted} in reduced water intake

Administration of L-Arg, but not D-Arg, in drinking water resulted in a significant decrease in average water intake for the group at the end of 4 weeks of treatment. The water intake, expressed as mean with their standard errors in $\mathrm{ml}$ at the start of the treatment (10 weeks) and at the end of the treatment (14 weeks), respectively, was as follows: control: 48 (SEM 2) $\mathrm{ml}$ and 50 (SEM 3) $\mathrm{ml}$ ( $n$ 8); L-Arg group: 68 (SEM 5) $\mathrm{ml}$ and 55 (SEM 2 ) $\mathrm{ml}(n$ 8); D-Arg group: 59 (SEM 4) $\mathrm{ml}$ and 56 (SEM 3 ) $\mathrm{ml}(n$ 8). The arginine dose was adjusted every other day by measuring the body weight and daily water intake using the formula: Body weight $\times 15 /$ water intake $/ \mathrm{d}=\mathrm{xxx} \mathrm{ml}$ of arginine $(10 \mathrm{~g} / \mathrm{l})$ to be added to a $300 \mathrm{ml}$ bottle with the rest tap water.

\section{Oral L-arginine reduces cationic transporter-1 expression in the ileum without any change in plasma and organ arginine concentrations}

Oral L-Arg or D-Arg did not affect arginine concentrations in the plasma, liver, ileum, kidney or the brain compared with the control group (Table 1). However, oral L-Arg and D-Arg significantly reduced the expression of CAT-1 in the liver, and L-Arg reduced it in the ileum as compared with the control (Fig. 1(a)). Expression of CAT-1 in the aorta was not significantly affected by oral L- or D-Arg (Fig. 1(a)).

\section{Effect of oral arginine on mean arterial pressure and the nitric oxide synthase-nitric oxide metabolic pathway}

Administration of oral L- or D-Arg did not affect the mean arterial pressure or the heart rate (Fig. 1(b)). However, L-Arg significantly increased eNOS expression in the aorta, and both L- and D-Arg significantly increased eNOS expression in the kidney, compared with the control (Fig. 1(c)). When NOS activity was measured, L- and D-Arg did not affect activity in the aorta, heart, kidney, liver, ileum, brain and the skeletal muscles (Table 1). Surprisingly, only D-Arg increased NOS activity in the lungs compared with the control and L-Arg groups (Table 1). L-Arg also significantly increased nitrite levels in the plasma compared with the control and D-Arg groups (Fig. 1(b)). Nitrite levels in the aorta, kidney, liver, ileum, brain, lungs and skeletal muscles were not affected by L- or D-Arg (Table 1). Interestingly, L-Arg at $1000 \mathrm{mg} / \mathrm{kg}$ per d for 12 weeks attenuated the increase in mean arterial pressure in Zucker diabetic fatty (ZDF) rats compared with D-Arg (unpublished results) (Data as mean values with their standard errors in $\mathrm{mmHg}$ : Zucker lean control: 98 (sem 4) mmHg ( $n$ 5); ZDF control: 118 (SEM 4) mmHg ( $n$ 4); ZDF + L-Arg: 93 (SEM 7) $\mathrm{mmHg}(n$ 4); ZDF + D-Arg: 105 (SEM 2) $\mathrm{mmHg}(n$ 3)). 

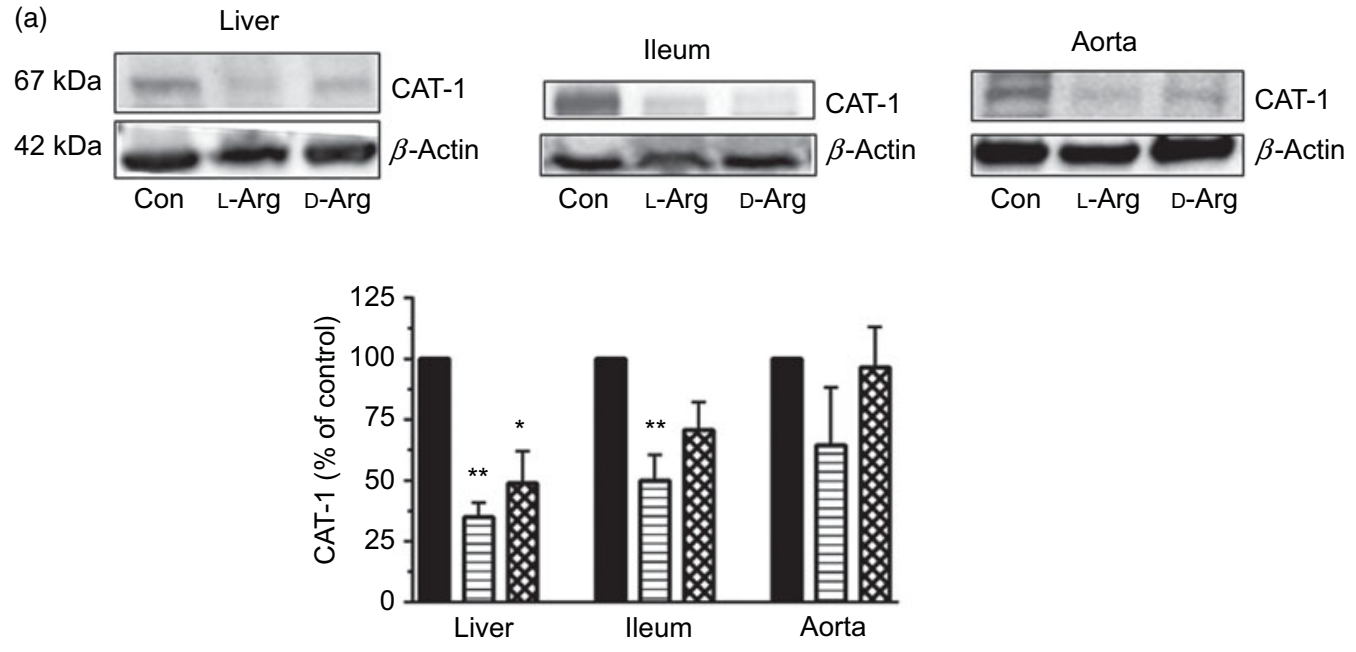

(b)
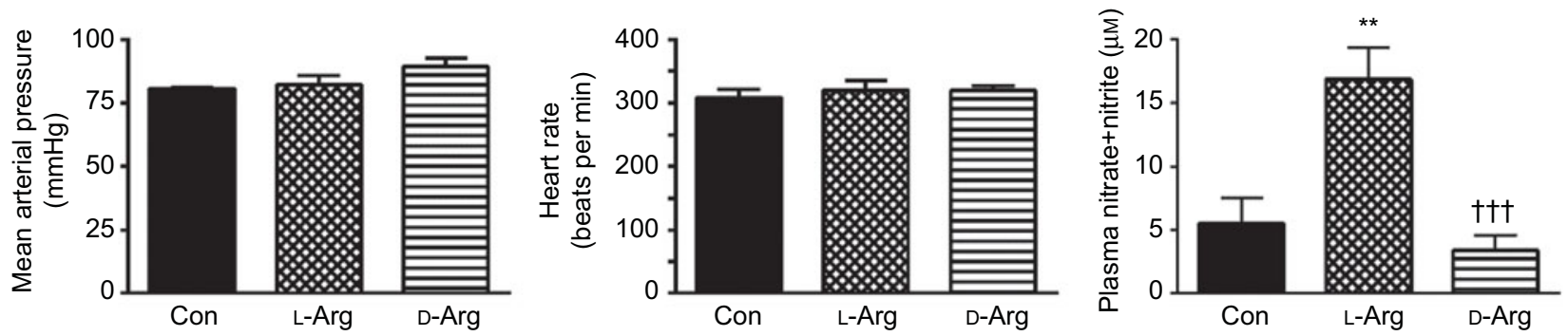

(c)
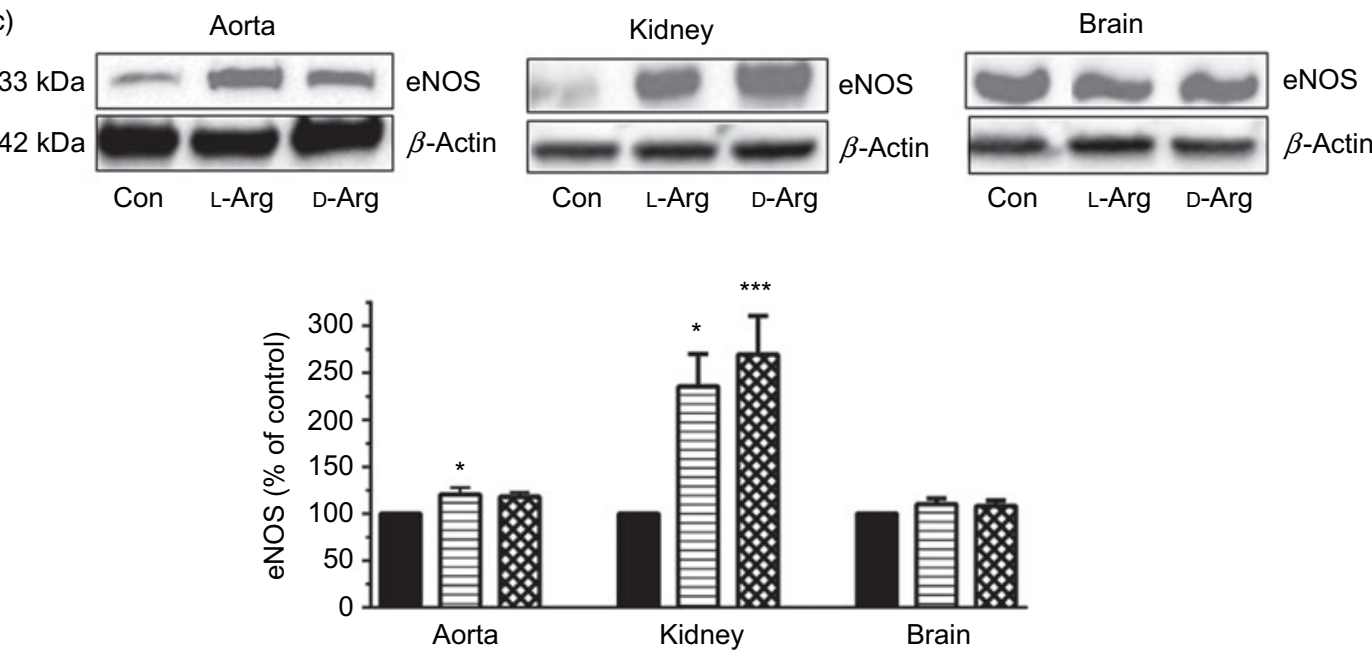

Fig. 1. Oral L-arginine (L-Arg) significantly reduces cationic transporter-1 (CAT-1) expression, increases endothelial nitric oxide synthase (eNOS) expression and plasma nitrite levels but does not affect not mean arterial pressure. Male Sprague-Dawley rats (10 weeks old) were treated with L-Arg or D-arginine (D-Arg) in drinking water $(500 \mathrm{mg} / \mathrm{kg}$ per d) for 4 weeks. Western blotting was used to determine expression of CAT-1 and eNOS (a, c). The blots were quantified using the GeneTools analysis software. Mean arterial pressure and heart rate were measured in anaesthetised rats with a carotid artery catheter (b). An assay kit with Griess reagent was used to measure nitrate + nitrite levels $(\mathrm{b})$. ${ }^{*} P<0.05$, ${ }^{* *} P<0.01$, ${ }^{* *} P<0.001 \mathrm{v}$. respective control (Con); ††† $P<0.001 \mathrm{v}$. respective L-Arg group.

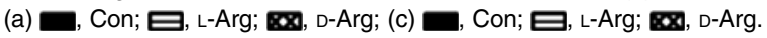

\section{Effect of oral $L$ - and D-arginine on the arginase-urea metabolic pathway}

Oral D-Arg significantly reduced the expression of arginase I in the liver compared with the control (Fig. 2(a)). Both L- and D-Arg significantly reduced the expression of arginase II in the ileum, but not in the kidney, compared with the control group (Fig. 2(a)). The arginase activity in the plasma, liver, kidney and ileum was not affected by either L- or D-Arg (Table 2). L- and D-Arg did not affect urea levels in the plasma, urine, lungs, brain and skeletal muscles as compared with the control (Fig. 2(b)). However, D-Arg, but not L-Arg, significantly increased urea levels in the liver as compared with the control, and the kidney as compared with the control and the L-Arg groups (Fig. 2(b)). 
Table 2. Effect of oral arginine on arginase activity and arginine decarboxylase protein levels† (Mean values with their standard errors; $n$ values)

\begin{tabular}{|c|c|c|c|c|c|c|c|c|c|}
\hline & \multicolumn{3}{|c|}{ Control } & \multicolumn{3}{|c|}{ L-Arginine } & \multicolumn{3}{|c|}{ D-Arginine } \\
\hline & Mean & SEM & $n$ & Mean & SEM & $n$ & Mean & SEM & $n$ \\
\hline \multicolumn{10}{|l|}{ Arginase activity } \\
\hline Plasma (mU/min per $\mathrm{ml})$ & 0.18 & 0.03 & 8 & 0.06 & 0.01 & 9 & 0.08 & 0.02 & 7 \\
\hline Liver (mU/min per mg protein) & 0.13 & 0.01 & 8 & 0.13 & 0.01 & 9 & 0.13 & 0.003 & 8 \\
\hline Ileum (mU/min per $\mathrm{mg}$ protein) & 0.05 & 0.006 & 8 & 0.05 & 0.002 & 7 & 0.05 & 0.005 & 8 \\
\hline Kidney (mU/min per mg protein) & 0.05 & 0.007 & 8 & 0.06 & 0.002 & 9 & 0.05 & 0.004 & 7 \\
\hline \multicolumn{10}{|l|}{ Arginine decarboxylase protein } \\
\hline Plasma (ng/ml) & 0.21 & 0.04 & 4 & 0.14 & 0.05 & 4 & 0.10 & 0.02 & 5 \\
\hline Liver (ng/mg protein) & $7 \cdot 2$ & 0.6 & 5 & 6.5 & 0.5 & 5 & 7.9 & 0.3 & 5 \\
\hline Ileum ( $\mathrm{ng} / \mathrm{mg}$ protein) & 0.35 & 0.09 & 5 & 0.52 & 0.17 & 5 & $0.79^{*}$ & 0.08 & 5 \\
\hline Kidney (ng/mg protein) & 9.9 & 0.6 & 4 & $9 \cdot 0$ & 1.4 & 5 & $11 \cdot 1$ & 0.6 & 4 \\
\hline Brain (ng/mg protein) & 0.38 & 0.02 & 5 & 0.33 & 0.05 & 5 & 0.38 & 0.02 & 5 \\
\hline
\end{tabular}

${ }^{*} P<0.05 v$. respective control group.

† Male Sprague-Dawley rats (10 weeks old) were treated with L-arginine or D-arginine in drinking water (500 mg/kg per d) for 4 weeks. An activity assay kit was used to measure arginase activity and an assay kit to measure arginine decarboxylase protein levels.

(a)
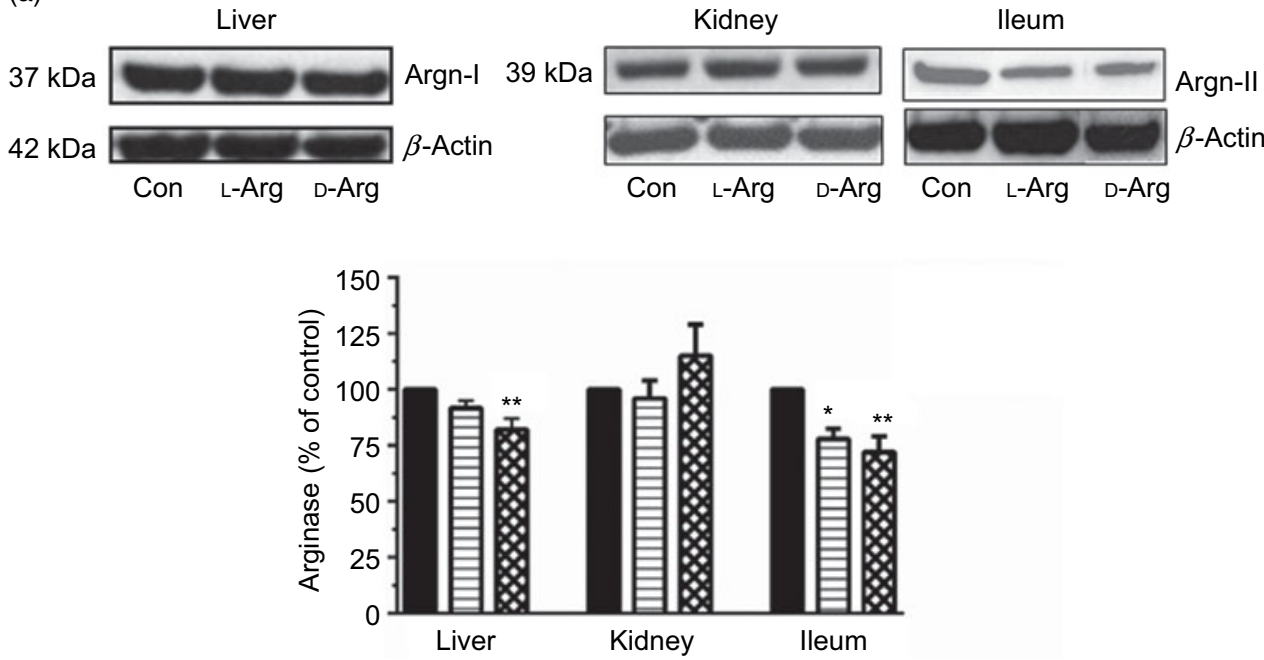

(b)
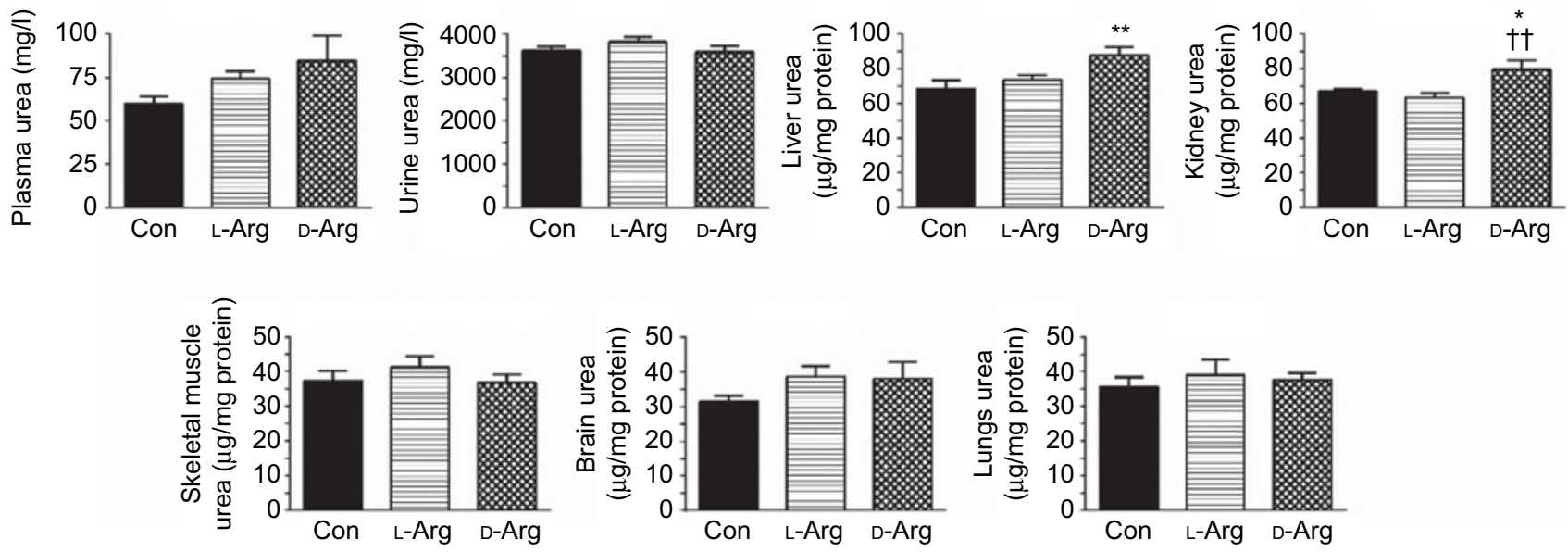

Fig. 2. Effect of oral arginine on arginase (Argn) expression and urea levels. Male Sprague-Dawley rats (10 weeks old) were treated with L-arginine (L-Arg) or $D$-arginine (D-Arg) in drinking water $(500 \mathrm{mg} / \mathrm{kg}$ per d) for 4 weeks. Western blotting was used to quantify arginase expression in the liver, kidney and ileum (a). The blots were quantified using the GeneTools analysis software. An assay kit was used to measure urea levels (b). ${ }^{*} P<0.05,{ }^{* *} P<0.01 \mathrm{v}$. respective control (Con); t† $P<0.01 v$. respective L-Arg group. (a) $\square$, Con; $\boxminus$, L-Arg; $\mathbf{\infty}, \mathrm{D}-\mathrm{Arg}$. 
(a)
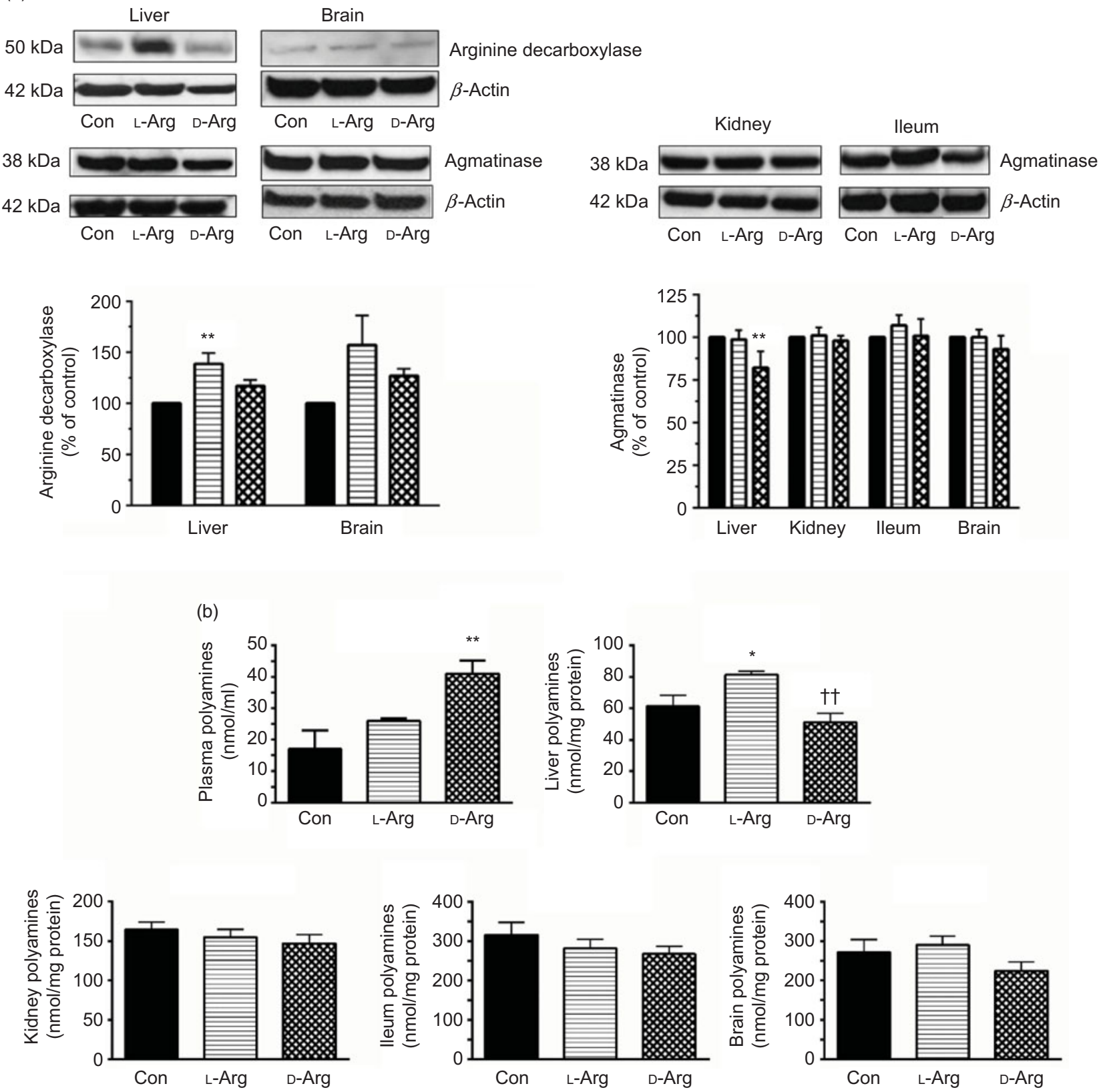

Fig. 3. Effect of oral arginine on arginine decarboxylase and agmatinase expression and polyamines levels. Male Sprague-Dawley rats (10 weeks old) were treated with L-arginine (L-Arg) or D-arginine (D-Arg) in drinking water $(500 \mathrm{mg} / \mathrm{kg}$ per d) for 4 weeks. Western blotting was used to quantify arginine decarboxylase and agmatinase expression in the liver, kidney, brain and ileum (a). The blots were quantified using the GeneTools analysis software. An assay kit was used to measure

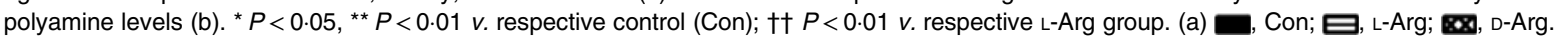

\section{Oral arginine and the arginine decarboxylase-agmatine metabolic pathway}

Oral L-Arg significantly increased the expression of ADC in the liver, but not in the brain, compared with the control group (Fig. 3(a)). On the other hand, D-Arg, but not L-Arg, significantly decreased the expression of agmatinase in the liver, compared with the control (Fig. 3(a)). L-Arg and D-Arg did not affect the expression of agmatinase in the kidney, ileum and the brain (Fig. 3(a)).
When ADC protein was measured with an assay kit, both L- and D-Arg did not affect levels in the plasma, liver, kidney and the brain (Table 2). However, D-Arg significantly increased ADC protein in the ileum compared with the control (Table 2).

D-Arg also significantly increased the levels of polyamines in the plasma compared with the control (Fig. 3(b)). In the liver, L-Arg significantly increased polyamines compared with the control and D-Arg decreased it compared with the L-Arg 
Table 3. Effect of oral arginine on creatinine and D-lactate levels $\dagger$ (Mean values with their standard errors; $n$ values)

\begin{tabular}{|c|c|c|c|c|c|c|c|c|c|}
\hline & \multicolumn{3}{|c|}{ Control } & \multicolumn{3}{|c|}{ L-Arginine } & \multicolumn{2}{|c|}{ D-Arginine } & \\
\hline & Mean & SEM & $n$ & Mean & SEM & $n$ & Mean & SEM & $n$ \\
\hline \multicolumn{10}{|l|}{ Creatinine } \\
\hline Plasma (mм) & 0.15 & 0.02 & 7 & 0.16 & 0.01 & 9 & 0.17 & 0.02 & 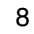 \\
\hline Urine (mм) & $10 \cdot 9$ & 0.3 & 8 & $10 \cdot 2$ & 0.6 & 9 & $10 \cdot 8$ & 0.4 & 8 \\
\hline Liver (nmol/mg protein) & $3 \cdot 1$ & 0.6 & 8 & $4 \cdot 8$ & 1.5 & 8 & $7 \cdot 8^{*}$ & 1.5 & 8 \\
\hline Ileum (nmol/mg protein) & $13 \cdot 9$ & $1 \cdot 3$ & 8 & $13 \cdot 4$ & $2 \cdot 7$ & 8 & $14 \cdot 2$ & $2 \cdot 0$ & 8 \\
\hline Kidney (nmol/mg protein) & $26 \cdot 4$ & $5 \cdot 0$ & 8 & $26 \cdot 9$ & 3.0 & 9 & $40 \cdot 9$ & $6 \cdot 5$ & 7 \\
\hline Skeletal muscle (nmol/mg protein) & 134 & 10 & 8 & $95^{*}$ & 10 & 9 & 105 & 7 & \\
\hline \multicolumn{10}{|l|}{ D-Lactate } \\
\hline Plasma ( $\mu \mathrm{M})$ & 62 & 11 & 7 & $87^{*}$ & 2 & 8 & 72 & 3 & 8 \\
\hline Urine $(\mu \mathrm{M})$ & 94 & 17 & 7 & 83 & 9 & 7 & 108 & 16 & 8 \\
\hline Liver (nmol/mg protein) & 45 & 5 & 6 & 42 & 3 & 6 & 44 & 4 & 6 \\
\hline Ileum (nmol/mg protein) & 32 & 2 & 5 & 33 & 5 & 6 & $27^{*}$ & 2 & 5 \\
\hline Kidney (nmol/mg protein) & 33 & 2 & 6 & 40 & 3 & 6 & $43^{*}$ & 3 & 6 \\
\hline Brain (nmol/mg protein) & 52 & 3 & 6 & $42^{*}$ & 3 & 6 & 46 & 3 & 6 \\
\hline
\end{tabular}

${ }^{*} P<0.05 \mathrm{v}$. respective control group.

† Male Sprague-Dawley rats ( 10 weeks old) were treated with L-arginine or D-arginine in drinking water ( $500 \mathrm{mg} / \mathrm{kg}$ per d) for 4 weeks. Assay kits were used to measure creatinine and D-lactate levels.
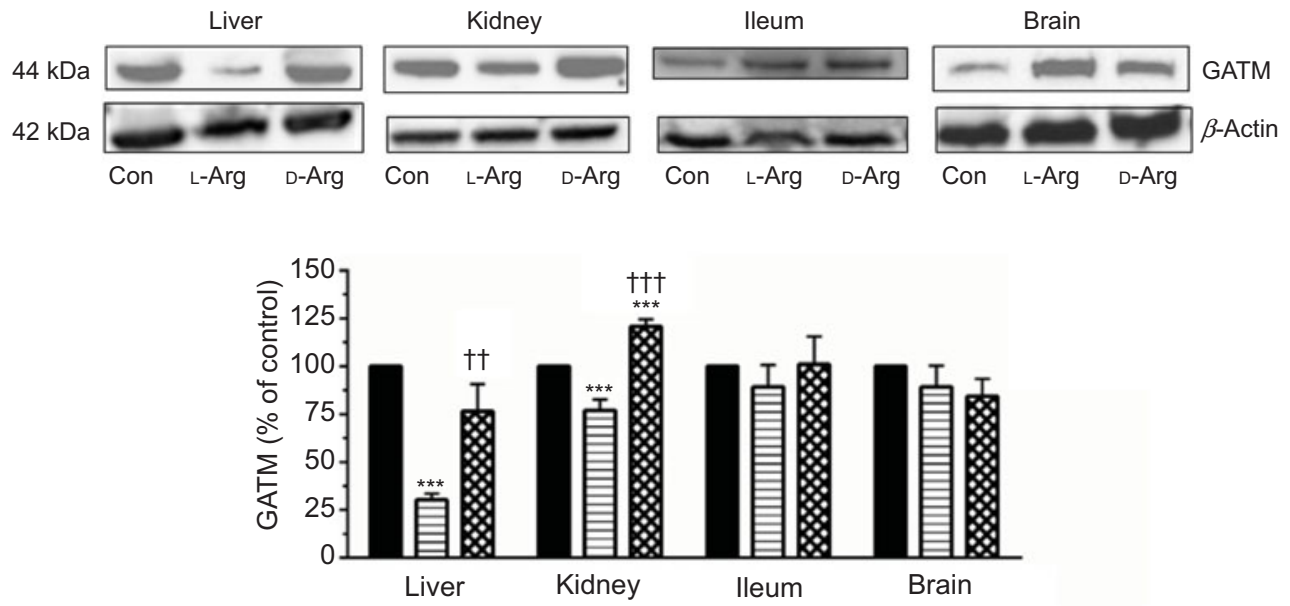

Fig. 4. Effect of oral arginine on arginine:glycine amidinotransferase (GATM) expression. Male Sprague-Dawley rats (10 weeks old) were treated with L-arginine (L-Arg) or D-arginine (D-Arg) in drinking water $(500 \mathrm{mg} / \mathrm{kg}$ per d) for 4 weeks. Western blotting was used to quantify GATM expression in the liver, kidney, ileum and brain (a). The blots were quantified using the GeneTools analysis software. ${ }^{* * *} P<0.01 \mathrm{v}$. respective control (Con); $\dagger \dagger P<0.01, \dagger \dagger \dagger P<0.001 \mathrm{v}$. respective L-Arg group. $\square$, Con; 目, L-Arg; $\boldsymbol{\infty}$, D-Arg.

group (Fig. 3(b)). Polyamine levels in the kidney, ileum and brain were not affected by L- and D-Arg (Fig. 3(b)).

\section{Oral arginine and the arginine:glycine amidinotransferase-creatine metabolic pathway}

Oral L-Arg significantly decreased the expression of GATM in the liver and the kidney, but not in the ileum and the brain, compared with the control (Fig. 4). On the other hand, D-Arg significantly increased the expression of GATM in the kidney compared with the control and L-Arg groups, but decreased it in the liver compared with the control (Fig. 4). Creatinine, a metabolite of creatine, levels in the plasma, urine kidney and ileum were not affected by L- Or D-Arg (Table 3). However, D-Arg significantly increased creatinine levels in the liver compared with the control, whereas L-Arg decreased it in the skeletal muscle compared with the control (Table 3).

\section{Effect of oral arginine on the glyoxalase-methylglyoxal- D-lactate metabolic pathway}

Both L- and D-Arg significantly decreased the expression of glyoxalase I in the liver and the ileum but not in the kidney, compared with the control (Fig. 5(a)). L-Arg, but not D-Arg, also significantly decreased the expression of glyoxalase I in the brain compared with the control (Fig. 5(a)).

L- and D-Arg significantly increased the activity of glyoxalase in the brain, but not in the liver, kidney or the ileum, when compared with the control (Fig. 5(b)). 
(a)
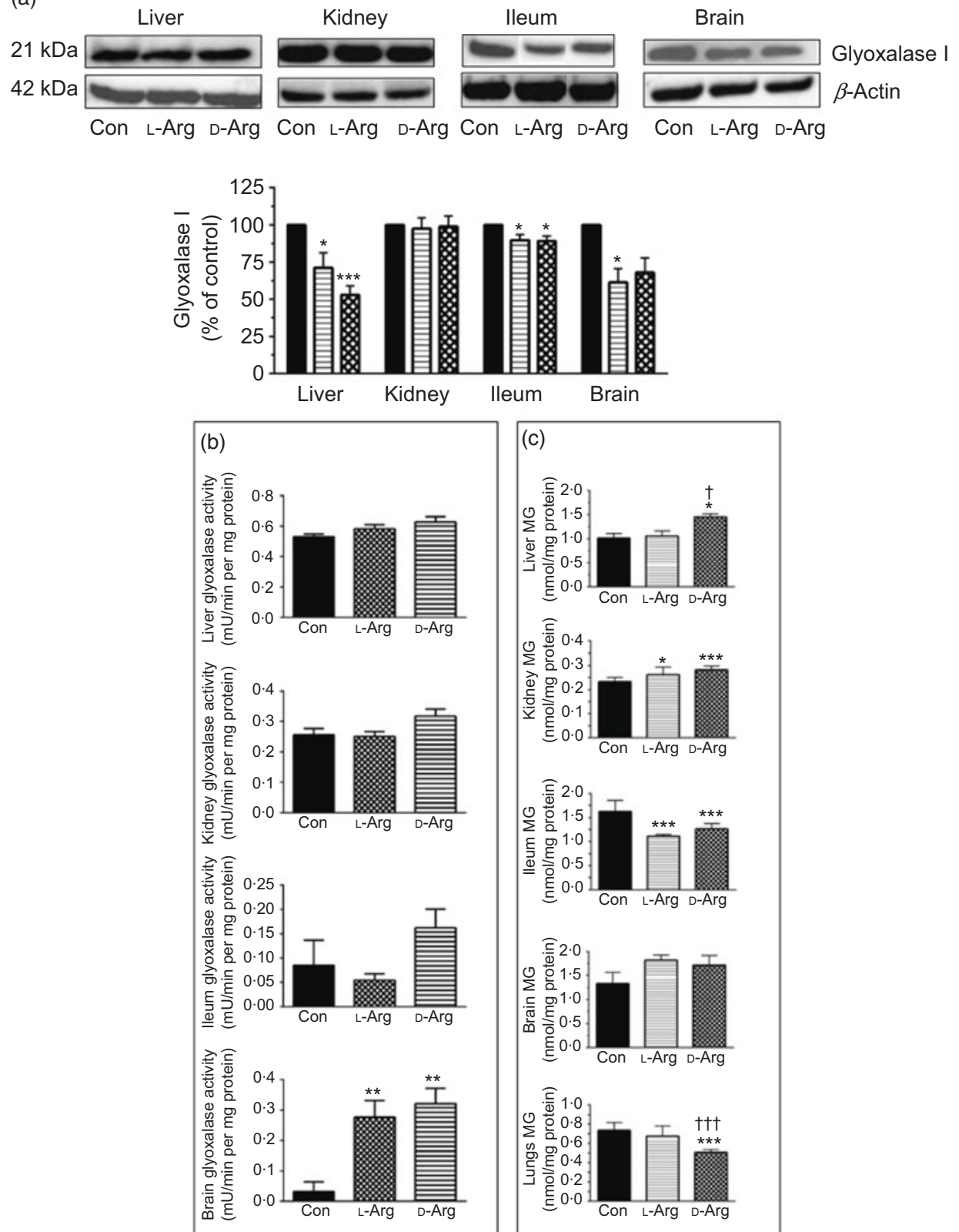

Fig. 5. Effect of oral arginine on glyoxalase I expression and activity and methylglyoxal (MG) levels. Male Sprague-Dawley rats (10 weeks old) were treated with L-arginine (L-Arg) or D-arginine (D-Arg) in drinking water $(500 \mathrm{mg} / \mathrm{kg}$ per d) for 4 weeks. Western blotting was used to quantify glyoxalase I expression in the liver, kidney, ileum and brain (a). The blots were quantified using the GeneTools analysis software. An activity assay kit was used to measure glyoxalase activity (b) and HPLC to measure MG levels (c). ${ }^{*} P<0.05,{ }^{* \star} P<0.01,{ }^{* *} P<0.001 \mathrm{v}$. respective control (Con); $\dagger P<0.05, \dagger \dagger \dagger P<0.001$ v. respective L-Arg group. (a) $\square$, Con; 曰, L-Arg; $\mathbf{2 0}$, D-Arg.

Both, L- and D-Arg significantly increased MG levels in the kidney and decreased them in the ileum, compared with the control (Fig. 5(c)). On the other hand, D-Arg significantly increased MG levels in the liver and decreased them in the lungs, compared with the control and L-Arg groups (Fig. 5(c)). MG levels in the brain were not affected by L- and D-Arg (Fig. 5(c)).

L-Arg, but not D-Arg, significantly increased D-lactate levels in the plasma compared with the control and significantly decreased them in the brain (Table 3). D-Arg significantly increased D-lactate levels in the kidney compared with the control (Table 3). D-lactate levels in the urine, liver and ileum were not affected by L- or D-Arg (Table 3).
Effect of oral arginine on lysine, asymmetric dimethyl arginine, citrulline, carbamoyl phosphate synthase-1 and hydroxyproline levels

Plasma lysine levels were significantly lower in the L-Arg group compared with the D-Arg group (Table 4). Oral L-Arg or D-Arg did not affect lysine levels in the liver or the ileum (Table 4). Asymmetric dimethyl arginine (ADMA) levels in the kidney were significantly higher in the L-Arg compared with the control and D-Arg groups (Table 4). ADMA levels in the plasma, liver and ileum were not different from each other in the three groups. L-Arg or D-Arg did not affect citrulline levels 
Table 4. Effect of oral arginine on lysine, asymmetric dimethyl arginine (ADMA), citrulline, carbamoyl phosphate-1 and hydroxyproline levelsł (Mean values with their standard errors; $n$ values)

\begin{tabular}{|c|c|c|c|c|c|c|c|c|c|}
\hline & \multicolumn{3}{|c|}{ Control } & \multicolumn{3}{|c|}{ L-Arginine } & \multicolumn{3}{|c|}{$\mathrm{D}$-Arginine } \\
\hline & Mean & SEM & $n$ & Mean & SEM & $n$ & Mean & SEM & $n$ \\
\hline \multicolumn{10}{|l|}{ Lysine } \\
\hline Plasma ( $\mu \mathrm{M})$ & 146 & 55 & 7 & 20 & 4 & 9 & $194 \dagger$ & 59 & 5 \\
\hline Liver (pmol/mg protein) & 403 & 70 & 5 & 433 & 106 & 5 & 341 & 50 & 5 \\
\hline Ileum (pmol/mg protein) & 1319 & 289 & 4 & 1140 & 175 & 5 & 698 & 33 & 5 \\
\hline \multicolumn{10}{|l|}{ ADMA } \\
\hline Plasma (ng/ml) & 293 & 88 & 8 & 277 & 87 & 8 & 445 & 86 & 8 \\
\hline Liver (ng/mg protein) & 20 & 1 & 7 & 18 & 1 & 7 & 20 & 1 & 5 \\
\hline Ileum (ng/mg protein) & 36 & 2 & 6 & 33 & 2 & 6 & 34 & 2 & 6 \\
\hline Kidney (ng/mg protein) & 64 & 3 & 6 & $78^{*}$ & 5 & 6 & $62 \dagger$ & 3 & 6 \\
\hline \multicolumn{10}{|l|}{ Citrulline } \\
\hline Plasma (mм) & $4 \cdot 6$ & 0.56 & 6 & $5 \cdot 7$ & $0 \cdot 70$ & 5 & 4.7 & 0.48 & 7 \\
\hline Liver ( $\mu \mathrm{mol} / \mathrm{mg}$ protein) & 50 & 17 & 6 & 38 & 6 & 6 & 28 & 4 & 6 \\
\hline Ileum ( $\mu \mathrm{mol} / \mathrm{mg}$ protein) & 15 & 2 & 6 & 21 & 4 & 7 & 21 & 4 & 6 \\
\hline Kidney ( $\mu \mathrm{mol} / \mathrm{mg}$ protein) & 268 & 113 & 5 & 216 & 16 & 6 & 178 & 19 & 6 \\
\hline \multicolumn{10}{|c|}{ Carbamoyl phosphate synthase- 1} \\
\hline Plasma (ng/ml) & 0.49 & $0 \cdot 16$ & 5 & 0.52 & $0 \cdot 11$ & 6 & $1.62^{*} \dagger$ & 0.35 & 8 \\
\hline Liver (ng/mg protein) & 0.37 & 0.05 & 8 & 0.37 & 0.06 & 8 & 0.34 & 0.04 & 8 \\
\hline lleum (ng/mg protein) & 0.14 & 0.02 & 6 & 0.10 & 0.01 & 6 & $0 \cdot 13$ & 0.03 & 5 \\
\hline Kidney (ng/mg protein) & 0.35 & 0.06 & 6 & 0.36 & 0.06 & 6 & 0.27 & 0.05 & 5 \\
\hline \multicolumn{10}{|l|}{ Hydroxyproline } \\
\hline Plasma (mм) & $2 \cdot 62$ & 0.04 & 7 & 4.18 & 1.08 & 8 & 5.02 & 1.17 & 8 \\
\hline Liver ( $\mu \mathrm{g} / \mathrm{mg}$ protein) & 31 & 19 & 6 & 105 & 38 & 8 & 102 & 56 & 4 \\
\hline lleum ( $\mu \mathrm{g} / \mathrm{mg}$ protein) & 217 & 59 & 7 & 156 & 85 & 3 & 145 & 53 & 5 \\
\hline Kidney ( $\mu \mathrm{g} / \mathrm{mg}$ protein) & 147 & 37 & 7 & 121 & 45 & 7 & 178 & 53 & 7 \\
\hline
\end{tabular}

${ }^{*} P<0.05 v$. respective control group.

$\dagger P<0.05 \mathrm{v}$. respective L-arginine group.

$\ddagger$ Male Sprague-Dawley rats ( 10 weeks old) were treated with L-arginine or D-arginine in drinking water (500 mg/kg per d) for 4 weeks. Assay kits were used to measure lysine, ADMA, citrulline, carbamoyl-phosphate-1 and hydroxyproline levels.

in the plasma, liver, ileum or the kidney (Table 4). Carbamoyl phosphate synthase-1 levels were significantly elevated in the D-Arg group compared with the control and L-Arg groups (Table 4). Finally, hydroxyproline levels were not affected in the plasma, liver, ileum or the kidney, either by L-Arg or D-Arg (Table 4)

\section{Discussion}

We report the metabolic effects of L-Arg and D-Arg administered for 4 weeks to Sprague-Dawley rats. Our comprehensive study reveals some novel and unusual findings with both isomers and will form the basis of the second phase of our study with a higher oral dose for a longer period. Both L- and D-Arg did not affect the normal plasma and organ levels of arginine as shown in Fig. 1(a). This is not surprising considering the fact that up to $40 \%$ of oral arginine is metabolised in the intestines before it reaches the systemic circulation ${ }^{(30)}$. The liver and the intestines have large amounts of arginase which is the major enzyme that uses arginine as a substrate ${ }^{(31)}$. Moreover, these arginases, possibly from erythrocytes, are also present in the plasma and as soon as arginine enters the circulation it may be getting metabolised. Also, arginine from the plasma would also be utilised by different organs and may not show elevated levels most of the time, except maybe within 15-30 min after absorption. Also, the plasma peaks after absorption would be smaller when arginine is given in drinking water rather than as a single large oral dose. Our plasma collection was at least
30 min after anaesthesia so plasma peaks from oral absorption would have subsided. Another reason for no change in plasma arginine could be the significant down-regulation of CAT- 1 in the ileum and the liver (Fig. 1(a)), which plays a role in arginine transport from the intestines ${ }^{(32)}$. This down-regulation of the transporter could be an adaptive response to deal with excess oral arginine. This also supports the observation that a deficiency of arginine has the opposite effect, that is, it up-regulates the CAT-1 gene and mRNA ${ }^{(33)}$. Since CAT-1 is a non-specific transporter, which also transports lysine ${ }^{(32)}$, our results showing significantly reduced plasma lysine in the L-Arg group compared with the D-Arg group (Table 4) support reduced transport by CAT-1. Reduced levels of the essential amino acid lysine, if reproduced in our next phase study with a $1000 \mathrm{mg}$ dose of L-Arg will be of concern. Similarly, glutamine transport and levels might also have been affected by oral arginine. One possible way to determine reduced absorption of oral arginine supplements would be to measure faecal arginine, which has been added to the protocol in the next phase of our study. Determination of glutamine levels will also be useful to support this.

One of the most popular metabolic pathways for which oral supplements are used is the NOS-NO pathway. As shown in Fig. 1(b), both $\mathrm{L}^{-}$and $\mathrm{D}$-Arg did not affect the mean arterial pressure or the heart rate. This supports the finding that oral arginine supplements do not lower blood pressure in healthy humans ${ }^{(14)}$, but may do so in some disease conditions in animals and humans ${ }^{(13)}$ (also supported by our unpublished results in 
ZDF rats). At the same time, we found significantly increased eNOS expression by L-Arg in the aorta and the kidney (Fig. 1(c)). This could be an adaptive response to increased substrate availability. The unusual finding here is that D-Arg also significantly increased eNOS expression in the kidney. D-Arg is not a substrate for the enzyme, and this perplexing finding requires further study and will be keenly observed in our second phase study with a higher dose. An increase in eNOS expression in the rabbit aorta by arginine supplements has been reported $^{(34)}$. The NOS activity in all the organs tested was not affected by L- or D-Arg, except in the lungs, where again unusually it was D-Arg that significantly increased it (Table 1). We do not wish to speculate on this finding but will see if it repeats with a higher dose in our second phase study. Whereas the eNOS expression in the aorta and kidney increased, there was no change in eNOS activity, which was matched by no increase in nitrates/nitrites. Such disparity between eNOS expression and activity has been observed before by Mohan et al. ${ }^{(35)}$ when exposure of cultured human endothelial cells to $50 \mu \mathrm{m}$ arginine increased eNOS activity but not protein or mRNA expression. When samples are prepared for enzyme activity assays, they are subject to several changes in their milieu despite strictly following protocols and that may adversely affect their activity. Others have also shown that oral L-Arg supplements do not affect eNOS activity in human subjects ${ }^{(10,19,21)}$. L-Arg significantly increased and D-Arg decreased plasma levels of nitrite (Table 1) but not in the organs tested including the aorta. The increase in plasma nitrite can be explained on the basis of the arginine paradox ${ }^{(36-38)}$ wherein it is believed that the caveolar eNOS in endothelial cells has easier access to plasma arginine due to co-localisation with CAT-1 in the caveoli ${ }^{(32)}$. Rapid utilisation of plasma arginine by eNOS and other enzymes such as arginases can also explain no change in plasma arginine levels (Table 1). Moreover, if most of the NO formed by caveolar eNOS is diffusing into the plasma rather than to the vascular smooth muscle, this can explain why there is no change in the mean arterial pressure.

The arginase-urea pathway is the major one which uses arginine as a substrate, yet any possible effect of oral supplements on this pathway is not normally known to the general public. We found that D-Arg, but not L-Arg, significantly reduced the expression of arginase I in the liver, whereas both $\mathrm{L}^{-}$and D-Arg reduced its expression in the ileum (Fig. 2(a)). Arginases have been reported to use $40 \%$ of the dietary arginine, which can explain significantly reduced absorption of oral arginine ${ }^{(39,40)}$. Moretto et al. ${ }^{(22)}$ found no change in liver arginase expression in rats with $2.25 \%$ arginine $(1.12 \mathrm{~g}$ with an assumed daily $50 \mathrm{ml}$ water intake) supplementation in drinking water. Arginine supplements would be expected to increase arginase expression, based on increased substrate-increased enzyme concept, but we saw the opposite with the liver and ileum arginases. Findings from our study with $1000 \mathrm{mg}$ arginine for 16 weeks, which is currently underway, will help us to make a more definite interpretation. The effect of D-Arg on arginase II in the ileum and arginase I in the liver is unexpected and along with its effect on other enzymes that use L-Arg demands further studies to see whether it competes with endogenous L-Arg for these enzymes as an inhibitor, an idea which we also treat with skepticism. Moretto et al. ${ }^{(22)}$ have reported a decrease in arginase activity in Wistar rats given chronic L-Arg supplements. The lack of effect of L- and D-Arg on kidney arginase II may possibly be due to not enough arginine reaching the kidney. L- and D-Arg did not affect arginase activity in the plasma, liver, ileum and kidney (Table 2). Even though L-Arg decreased arginase II expression in the ileum (Fig. 2(a)), there was no change in activity (Table 2 ). We have previously seen a mismatch between arginase expression and its activity in cultured human umbilical vein endothelial cells and also in rat vascular smooth muscle cells treated with high glucose and high glucose + L-Arg or D-Arg, where high glucose increased expression more than glucose plus L-Arg or D-Arg, but activity was significantly more in high glucose plus L-Arg or D-Arg groups than in high glucose alone group ${ }^{(23)}$. A similar mismatch between arginase expression and its activity was observed in several organs by Moretto et al. ${ }^{(22)}$. For example, in the brain, they found that L-Arg supplements increased arginase II expression but the activity was unchanged ${ }^{(22)}$. Thus, arginase I and II seem to have differential regulation not only from each other but also from organ to organ. L- and D-Arg did not affect the urea levels in the plasma, urine and organs such as the liver, lungs, brain and skeletal muscles. Unusually, one more time, D-Arg increased urea levels in the kidney (Fig. 2(b)) even though there was no effect on arginase II expression (Fig. 2(a)). The increase in urea levels by D-Arg only in the kidney, with no change in arginase activity, can be explained by a compensatory reduced expression of hepatic arginase and a possible, but unproven, increased hepatic glutamine synthesis and elimination of ammonia. It should be pointed out that arginine is believed to exist in separate pools within the cells and different pools contribute to the function of different enzymes. Thus, it has been shown that metabolites produced and used by the urea cycle enzymes are recycled and this includes arginine which is synthesised and used within this cycle and is not influenced by exogenous arginine or free arginine within the $\left.\operatorname{cytosol}^{(9}, 41\right)$. This may be a reason why we did not see any changes in carbamoyl phosphate synthase 1 or citrulline levels in the liver, ileum and kidney in L-Arg and D-Arg groups (Table 4). Since citrulline is also a product of NOS enzymes, any changes in citrulline levels in any organ become useful parameters of changes in NOS or arginase activity. We do not have any explanation for the significantly increased carbamoyl phosphate synthase 1 levels in the plasma in the D-Arg group. We will see if we get a similar result in the next phase of our study with a higher oral dose of arginine administered for a longer period in SpragueDawley rats.

The ADC and agmatinase enzymes produce agmatine from L-Arg ${ }^{(8,9)}$. L-Arg significantly increased ADC expression in the liver, but not in the brain, possibly due to increased substrate availability during first pass through the liver after absorption (Fig. 3(a)). Arginine decarboxylase levels measured by an ELISA kit did not show significant changes in the expression of the enzyme in the liver (Table 2). One possible reason could be that the ELISA depends on enzymatic activity which might have altered in the assay conditions. D-Arg also decreased agmatinase expression in the liver (Fig. 3(a)) adding to the growing list of unexpected effects of oral D-Arg. L-Arg did not 
affect agmatinase levels (Fig. 3(a)). We could not analyse agmatine levels reproducibly with HPLC, but when we analysed polyamines, which are downstream products of agmatine as well as ornithine, we found significant increase by L-Arg in the liver (Fig. 3(b)), which can be explained by the increased expression of ADC (Fig. 3(a)). Ornithine generated from arginase is also a source of polyamines, but arginase expression in the liver was not increased by L-Arg in our study. The increase in plasma polyamine levels by D-Arg (Fig. 3(b)) cannot be explained and will be observed closely in our second phase higher dose study. The significant increase in liver polyamines could be a cause for concern due to their role in cell proliferation and tumour development ${ }^{(1)}$. Since ornithine is also a precursor for proline synthesis $^{(1)}$, we measured hydroxyproline levels (Table 4). Although the levels were not significantly different between the three groups in the plasma, liver, ileum and kidney, the levels in the L-Arg and D-Arg groups showed a trend towards increase in the plasma and the liver. Due to large variability, the differences did not reach significance. Due to the role of proline in collagen synthesis, any changes in proline levels are of interest from the point of view of wound and tissue repair.

L-Arg caused a significant decrease in the expression of GATM in the liver and the kidney, but the creatinine levels were not affected (Fig. 4, Table 3), whereas D-Arg caused a significant increase in the kidney (Fig. 4). D-Arg significantly increased creatinine levels in the liver (Table 3) which is beyond explanation at this stage and requires further studies with cultured cells.

We have shown earlier that L-Arg and D-Arg are MG scavengers ${ }^{(23)}$, and MG is mostly degraded by the glyoxalase enzymes to produce the inert D-lactate ${ }^{(42)}$. L-Arg significantly decreased the expression of glyoxalase I in the liver, ileum and the brain (Fig. 5(a)). The activity was significantly increased by L- and D-Arg in the brain (Fig. 5(b)). The change in expression of glyoxalase I in the liver, ileum and the brain was not matched by a corresponding change in their activities in these organs (Fig. 5). A similar mismatch between expression and activities of glyoxalase I was reported by Kuhla et $a l .{ }^{(43)}$. They attributed it to several possible post-translational influences, such as phosphorylation of the enzyme by cytokines, during in vitro activity assay, which seems a reasonable explanation for the mismatch we also observed. D-Arg significantly increased MG levels in the liver, but decreased it in the lungs (Fig. 5(c)). Both L- and D-Arg increased MG levels in the kidney but decreased it in the ileum (Fig. 5(c)). L-Arg increased D-lactate levels in the plasma but decreased them in the brain, whereas D-Arg increased them in the kidney (Table 3). Since the ileum is likely to receive most of the orally absorbed arginine and since both $\mathrm{L}$ - and $\mathrm{D}$-Arg can scavenge $\mathrm{MG}^{(23)}$, it explains the significant decrease of MG caused by both isomers in the ileum (Fig. 5(c)). This decrease in MG by both isomers might also explain the decreased expression of glyoxalase I in the ileum (Fig. 5(a)), which is the primary catabolic enzyme for $\mathrm{MG}^{(42)}$. The decrease in glyoxalase I expression in the liver caused by L- and D-Arg without any change in activity or D-lactate levels is difficult to explain (Fig. 5, Table 3). Little is known about intracellular production of MG in different organs and whether it is transported out of the cell which makes it difficult to explain or predict its interaction with different arginine pools.

ADMA levels in the plasma, liver or ileum were not affected by oral L-Arg or D-Arg (Table 4); however, the ADMA levels in the kidney were significantly higher in the L-Arg group (Table 4). It is possible that guanidinoacetate methyltransferase might have contributed to ADMA synthesis from L-Arg ${ }^{(44)}$ in the kidney, which has high activity of this enzyme ${ }^{(7)}$. It has been shown that free L-Arg in the plasma can be metabolised to $\mathrm{ADMA}^{(44)}$ but we did not see any change in plasma ADMA levels. ADMA levels are of interest because of their ability to inhibit NOS enzymes and cause dysfunction ${ }^{(45)}$.

The dose of $500 \mathrm{mg} / \mathrm{kg}$ per $\mathrm{d}$ used in our study converts to an equivalent dose of about $81 \mathrm{mg} / \mathrm{kg}$ per $\mathrm{d}$ for humans (approximately $5.6 \mathrm{~g}$ for a $70 \mathrm{~kg}$ adult), according to the FDA conversion guide ${ }^{(46)}$. Thus, the dose used by us is relatively small for human equivalent dose. Wu et al. ${ }^{(40)}$ reported the use of $1.8 \mathrm{~kg} / \mathrm{d}$ (human equivalent dose of $20 \mathrm{~g} / \mathrm{d}$ for a $70 \mathrm{~kg}$ adult) of arginine base oral supplementation for $91 \mathrm{~d}$ in female rats to be safe. In another study, Yang et $a l^{(47)}$ used doses of 1.8 and $3.6 \mathrm{~g} / \mathrm{kg}$ per $\mathrm{d}$ (equivalent human dose of $40 \mathrm{~g} / \mathrm{d}$ for a $70 \mathrm{~kg}$ adult) of $\mathrm{L}$-Arg $\mathrm{HCl}$ in rats in drinking water for 13 weeks. They reported changes in levels ornithine, proline, homoarginine, urea and NO metabolites and also GATM activity in the kidneys, and yet they concluded that it was a safe dose in rats. Doses of 6-9 g/d for periods ranging from $21 \mathrm{~d}$ to 18 months have been used in human studies without any remarkable adverse effects ${ }^{(48)}$. McNeal et al. ${ }^{(48)}$ report a dose of about $20 \mathrm{~g} / \mathrm{d}$ as safe in humans. A meta analysis of eleven trials on the effect of arginine supplements on blood pressure used arginine doses ranging from 4 to $24 \mathrm{~g} / \mathrm{d}$ in humans for periods ranging from 2 to 24 weeks $^{(13)}$.

In conclusion, our data reveal significant impacts on several enzymes and metabolites in different organs that use L-Arg as a substrate. The effects on enzymes and their metabolites do not appear to follow a pattern, which is perplexing, but support mismatched effects, reported by Moretto et $a l^{(22)}$, on arginase activity and expression in different organs by oral arginine. The mismatched effects also support the proposal that L-Arg is highly compartmentalised for different enzymes in different organs ${ }^{(9,37)}$. The inclusion of $\mathrm{D}$-Arg in our studies discloses some unexpected and novel effects and emphasises more dynamic enzyme-substrate kinetics for arginine metabolic pathways than that currently known. The arginine metabolic pathways in the ileum and the liver undergo most changes and can be explained by exposure to larger amounts of orally absorbed arginine. The oral route chosen by us also makes our results relevant to the use of oral arginine as a nutrient, especially as an ergogenic aid. Even with this low dose and only 4 weeks of treatment, we observed changes in the expression of enzymes such as arginase and ADC, and levels of other parameters and we hesitate to say that an equivalent human dose of about $5.6 \mathrm{~g} / \mathrm{d}$ is safe. Arginase is an important enzyme that utilises the majority of dietary and supplemental arginine and maybe stealing NO from NOS enzymes ${ }^{(31,38)}$. We will be able to make a more definitive statement about safety and effectiveness following our studies with $500 \mathrm{mg} / \mathrm{kg}$ per $\mathrm{d}$ for 16 weeks and 
$1000 \mathrm{mg} / \mathrm{kg}$ per $\mathrm{d}$ for 16 weeks in rats, which are currently underway. Thus, our data make a significant contribution to the knowledge regarding the impact of oral arginine supplements and will go towards building a scientific basis on its safety and effective use.

\section{Acknowledgements}

We acknowledge the advice provided by Dr George Katselis and Dr Stan Bardal. We are grateful for the support provided by the vivarium staff.

This work was funded by a Discovery grant from Natural Sciences and Engineering Council of Canada (NSERC, grant no. RGPIN-2016-03951).

S. M. was supported by a College of Medicine graduate award (ComGRAD) for 2 years.

K. D. developed original research idea and protocols, helped with in vivo experiments and bioassays, analysed data and edited the manuscript. S. M. carried out the experiments, analysed data and wrote the first draft of the manuscript

All authors have no conflicts of interest.

\section{References}

1. Morris SM (2007) Arginine metabolism: boundaries of our knowledge. J Nutr 137, 1602S-1609S.

2. Palmer RM, Ashton DS \& Moncada S (1988) Vascular endothelial cells synthesize nitric oxide from L-arginine. Nature 333, 664-666.

3. Lekakis JP, Papathanassiou S, Papaioannou TG, et al. (2002) Oral $\mathrm{L}$-arginine improves endothelial dysfunction in patients with essential hypertension. Int J Cardiol 86, 317-323.

4. Creager MA, Gallagher SJ, Girerd XJ, et al. (1992) L-Arginine improves endothelium-dependent vasodilation in hypercholesterolemic humans. J Clin Invest 90, 1248-1253.

5. Maxwell AJ, Ho HV, Le CQ, et al. (2001) L-Arginine enhances aerobic exercise capacity in association with augmented nitric oxide production. J Appl Physiol 90, 933-938.

6. Berkowitz DE, White R, Li D, et al. (2003) Arginase reciprocally regulates nitric oxide synthase activity and contributes to endothelial dysfunction in aging blood vessels. Circulation 108, 2000-2006.

7. Van Pilsum JF, Stephens GC \& Taylor D (1972) Distribution of creatine, guanidinoacetate and enzymes for their biosynthesis in the animal kingdom. Implications for phylogeny. Biochem J 126, 325-345.

8. Li G, Regunathan S, Barrow CJ, et al. (1994) Agmatine: an endogenous clonidine-displacing substance in the brain. Science 263, 966-969.

9. Morris SM Jr (2016) Arginine metabolism revisited. J Nutr 146 , 2579S-2586S

10. Alvares TS, Meirelles CM, Bhambhani YN, et al. (2011) L-Arginine as a potential ergogenic aid in healthy subjects. Sports Med 41, 233-248.

11. Koga Y, Akita Y, Junko N, et al. (2006) Endothelial dysfunction in MELAS improved by L-arginine supplementation. Neurology 66, 1766-1769.

12. Piatti PM, Monti LD, Valsecchi G, et al. (2001) Long-term oral L-arginine administration improves peripheral and hepatic insulin sensitivity in type 2 diabetic patients. Diabetes Care $\mathbf{2 4}$, 875-880.

13. Dong JY, Qin LQ, Zhang Z, et al. (2011) Effect of oral L-arginine supplementation on blood pressure: a meta-analysis of randomized, double-blind, placebo-controlled trials. $A m$ Heart J 162, 959-965.

14. Ast J, Cieslewicz AR, Korzeniowska K, et al. (2011) Supplementation with L-arginine does not influence arterial blood pressure in healthy people: a randomized, double blind, trial. Eur Rev Med Pharmacol Sci 15, 1375-1384.

15. McKnight JR, Satterfield MC, Jobgen WS, et al. (2010) Beneficial effects of L-arginine on reducing obesity: potential mechanisms and important implications for human health. Amino Acids 39, 349-357.

16. Lucotti P, Setola E, Monti LD, et al. (2006) Beneficial effects of a long-term oral L-arginine treatment added to a hypocaloric diet and exercise training program in obese, insulin-resistant type 2 diabetic patients. Am J Physiol Endocrinol Metab 291, E906-E912.

17. Schulze F, Glos S, Petruschka D, et al. (2009) L-Arginine enhances the triglyceride-lowering effect of simvastatin in patients with elevated plasma triglycerides. Nutr Res 29, 291-297.

18. Blum A, Hathaway L, Mincemoyer R, et al. (2000) Oral L-arginine in patients with coronary artery disease on medical management. Circulation 101, 2160-2164.

19. Bennett-Richards KJ, Kattenhorn M, Donald AE, et al. (2002) Oral L-arginine does not improve endothelial dysfunction in children with chronic renal failure. Kidney Int 62, 1372-1378.

20. Walker HA, McGing E, Fisher I, et al. (2001) Endotheliumdependent vasodilation is independent of the plasma L-arginine/ADMA ratio in men with stable angina: lack of effect of oral L-arginine on endothelial function, oxidative stress and exercise performance. J Am Coll Cardiol 38, 499-505.

21. Alvares TS, Conte-Junior CA, Silva JT, et al. (2014) L-Arginine does not improve biochemical and hormonal response in trained runners after 4 weeks of supplementation. Nutr Res 34, 31-39.

22. Moretto J, Guglielmetti AS, Tournier-Nappey M, et al. (2017) Effects of a chronic L-arginine supplementation on the arginase pathway in aged rats. Exp Gerontol 90, 52-60.

23. Dhar I, Dhar A, Wu L, et al. (2012) Arginine attenuates methylglyoxal- and high glucose-induced endothelial dysfunction and oxidative stress by an endothelial nitric-oxide synthase-independent mechanism. J Pharmacol Exp Ther 342 , 196-204.

24. Iannaccone PM \& Jacob HJ (2009) Rats! Dis Model Mech 2, 206-210.

25. Kilkenny C, Browne WJ, Cuthill IC, et al. (2010) Improving bioscience research reporting: The ARRIVE guidelines for reporting animal research. J Pharmacol Pharmacother 1, 94-99.

26. Xu X, Zhao W, Lao S, et al. (2010) Effects of exercise and L-arginine on ventricular remodeling and oxidative stress. Med Sci Sports Exerc 42, 346-354.

27. Lee CW, Li D, Channon KM, et al. (2009) L-Arginine supplementation reduces cardiac noradrenergic neurotransmission in spontaneously hypertensive rats. J Mol Cell Cardiol 47, 149-155.

28. Matsuoka H, Nakata M, Kohno K, et al. (1996) Chronic L-arginine administration attenuates cardiac hypertrophy in spontaneously hypertensive rats. Hypertension 27, 14-18.

29. Clarkson P, Adams MR, Powe AJ, et al. (1996) Oral L-arginine improves endothelium-dependent dilation in hypercholesterolemic young adults. I Clin Invest 97, 1989-1994.

30. Castillo L, Chapman TE, Sanchez M, et al. (1993) Plasma arginine and citrulline kinetics in adults given adequate and arginine-free diets. Proc Natl Acad Sci U S A 90, 7749-7753.

31. Morris SM Jr (2009) Recent advances in arginine metabolism: roles and regulation of the arginases. BrJ Pharmacol 157, 922-930 
32. Closs EI, Simon A, Vekony N, et al. (2004) Plasma membrane transporters for arginine. J Nutr 134, 2752S-2759S; discussion 2765S-2767S.

33. Fernandez J, Lopez B, Wang C, et al. (2003) Transcriptional control of the arginine/lysine transporter, Cat-1, by physiological stress. J Biol Chem 278, 50000-50009.

34. Javanmard SH, Nematbakhsh M, Mahmoodi F, et al. (2009) L-Arginine supplementation enhances eNOS expression in experimental model of hypercholesterolemic rabbits aorta. Pathophysiology 16, 9-13.

35. Mohan S, Wu CC, Shin S, et al. (2012) Continuous exposure to L-arginine induces oxidative stress and physiological tolerance in cultured human endothelial cells. Amino Acids 43, 1179-1188.

36. Shin S, Mohan S \& Fung HL (2011) Intracellular L-arginine concentration does not determine NO production in endothelial cells: implications on the "L-arginine paradox". Biochem Biophys Res Commun 414, 660-663.

37. Simon A, Plies L, Habermeier A, et al. (2003) Role of neutral amino acid transport and protein breakdown for substrate supply of nitric oxide synthase in human endothelial cells. Circ Res 93, 813-820.

38. Dioguardi FS (2011) To give or not to give? Lessons from the arginine paradox. J Nutrigenet Nutrigenomics $\mathbf{4}, 90-98$.

39. Castillo L, Chapman TE, Yu YM, et al. (1993) Dietary arginine uptake by the splanchnic region in adult humans. Am J Physiol 265, E532-E539.

40. Wu Z, Hou Y, Hu S, et al. (2016) Catabolism and safety of supplemental L-arginine in animals. Amino Acids 48, 1541-1552.
41. Cheung CW, Cohen NS \& Raijman L (1989) Channeling of urea cycle intermediates in situ in permeabilized hepatocytes. J Biol Chem 264, 4038-4044.

42. Desai K \& Wu L (2007) Methylglyoxal and advanced glycation endproducts: new therapeutic horizons? Rec Pat Cardiovas Drug Dis 2, 89-99.

43. Kuhla B, Boeck K, Schmidt A, et al. (2007) Age- and stagedependent glyoxalase I expression and its activity in normal and Alzheimer's disease brains. Neurobiol Ageing 28, 29-41.

44. Kayacelebi AA, Langen J, Weigt-Usinger K, et al. (2015) Biosynthesis of homoarginine (hArg) and asymmetric dimethylarginine (ADMA) from acutely and chronically administered free L-arginine in humans. Amino Acids $\mathbf{4 7}$, $1893-1908$.

45. Leiper J \& Vallance P (1999) Biological significance of endogenous methylarginines that inhibit nitric oxide synthases. Cardiovas Res $\mathbf{4 3}, 542-548$.

46. FDA Center for Drug Evaluation and Research (CDER), US Department for Health and Human Services (2005) Guidance for industry: estimating the maximum safe starting dose in initial clinical trials for therapeutics in adult healthy volunteers. http:// www.fda.gov/cdev/guidance/index.htm (accessed September 2019).

47. Yang Y, Wu Z, Jia S, et al. (2015) Safety of long-term dietary supplementation with L-arginine in rats. Amino Acids $\mathbf{4 7}$, 1909-1920.

48. McNeal CJ, Meininger CJ, Reddy D, et al. (2016) Safety and effectiveness of arginine in adults. J Nutr $\mathbf{1 4 6}$, 2587S-2593S. 